\title{
Minimizing the risk of hypoglycemia in patients with type 2 diabetes mellitus
}

This article was published in the following Dove Press journal:

Diabetes, Metabolic Syndrome and Obesity:Targets and Therapy 16 March 201 I

Number of times this article has been viewed

\author{
Pamela Kushner \\ University of California, Irvine \\ College of Medicine, California, USA
}

Correspondence: Pamela Kushner 2865 Atlantic Avenue, Suite 207, Long Beach, CA 90806

Tel + I 5625956770

Fax + I 5625955553

Email pamkushner@hotmail.com

\begin{abstract}
Hypoglycemia is a major barrier to achieving glycemic goals in patients with diabetes. Both acute and chronically recurrent hypoglycemic events appear to have long-term consequences for patients with type 2 diabetes mellitus (T2DM). Chronically recurrent hypoglycemia may lead to an impairment of the counterregulatory system, with the potential for the development of hypoglycemia unawareness syndrome, increased severe hypoglycemia-associated hospitalization, and increased mortality. Hypoglycemic events may also have negative implications in cardiovascular disease and/or dementia. Avoidance of hypoglycemia by treating with appropriate, individualized regimens for patients with T2DM should be a primary focus of physicians. Utilizing traditional agents (eg, metformin and thiazolidinediones) that do not promote hypoglycemia, in combination with newer agents such as dipeptidyl peptidase-4 inhibitors and incretin mimetics, could offer a therapeutic advantage when trying to help patients reach their hemoglobin $\mathrm{A}_{1 \mathrm{c}}$ goal without the added risk of hypoglycemia.
\end{abstract}

Keywords: hypoglycemia, type 2 diabetes mellitus, incretin, dipeptidyl peptidase- 4 inhibitors, diabetes management

\section{Introduction}

Hypoglycemia is a major barrier to care for physicians and their patients with type 2 diabetes mellitus (T2DM). Physicians and patients have attempted to minimize hypoglycemic episodes while managing blood glucose; however, for some patients the consequences of hypoglycemia extend beyond the classic signs and symptoms and may include increased mortality risk. ${ }^{1-3}$ Certain agents prescribed for T2DM significantly increase the risk of hypoglycemia; sulfonylureas and meglitinides are among these agents. Furthermore, some patients with diabetes mellitus may have a compromised hypoglycemic counterregulatory system, limiting self-awareness of a hypoglycemic attack, often called hypoglycemia unawareness syndrome. ${ }^{4,5}$ Recognizing risk factors for hypoglycemia and selecting an appropriate, patient-focused regimen are key steps in avoiding these life-altering complications. The purpose of this paper is to offer suggestions for minimizing the risk of hypoglycemia utilizing currently available agents while still providing adequate blood glucose control.

\section{Hypoglycemia}

\section{Signs, symptoms, and possible sequelae}

Clinical hypoglycemia is characterized by Whipple's triad, ie, signs and/or symptoms known or likely to be caused by hypoglycemia, a low plasma glucose level, and cessation of signs or symptoms after plasma glucose is raised..$^{5}$ The signs and 
symptoms of hypoglycemia include those secondary to activation of the autonomic nervous system and neuroglycopenia (Figure 1). ${ }^{6,7}$

The body's defenses against hypoglycemia include decreased insulin secretion, increased glucagon secretion, and, when glucagon fails, increased serum epinephrine. ${ }^{5}$ In older patients and in patients who have a history of recurrent hypoglycemia, autonomic dysfunction can blunt or distort the response, making self-recognition of hypoglycemia more difficult. Hypoglycemia unawareness syndrome can delay a patient's corrective behavioral action (ie, carbohydrate ingestion) and subsequently may cause confusion and an inability to correct the hypoglycemic state, possibly contributing to morbidity or mortality. 4,5

\section{Prevalence, morbidity, and mortality}

Although morbidity and mortality attributable to hypoglycemia are less frequent in patients with T2DM than in those with type 1 diabetes, some T2DM patient populations (eg, those with advanced microvascular or macrovascular complications, extensive comorbid conditions, or long-standing diabetes mellitus) may exhibit a higher risk for morbidity and death from hypoglycemia. ${ }^{3}$ Recently, in the Veterans Affairs Diabetes Trial, severe hypoglycemic events were demonstrated to be a strong predictor of a composite endpoint of cardiovascular disease (CVD) events and CVD mortality in intensively treated patients (hemoglobin $\mathrm{A}_{1 \mathrm{c}}\left[\mathrm{HbA}_{1 \mathrm{c}}\right]$ goal $<6 \%$ ) and of all-cause mortality in patients in the standard treatment arm. ${ }^{3}$
The Action to Control Cardiovascular Risk in Diabetes trial was stopped early when it was found that the total mortality rate due to any cardiovascular cause was significantly greater in the intensive treatment group versus the standard treatment group. ${ }^{1}$ It was hypothesized that the greater frequency of severe hypoglycemia in the intensively treated group compared with the standard treatment group (10.5\% versus $3.5 \%, P<0.001)$ may have contributed to the excess mortality. ${ }^{2}$ Upon retrospective analysis of the data, researchers reported that severe hypoglycemia alone did not account for the difference in mortality between the two study groups. ${ }^{8}$ In fact, among patients who experienced an episode of severe hypoglycemia, the relative risk of death was lower in the intensive treatment group than in the standard arm, demonstrating that patients with T2DM who experience symptomatic, severe hypoglycemia are at increased risk of death regardless of intensity of glycemic control. ${ }^{8}$ Furthermore, a retrospective analysis showed patients with poorer glycemic control (higher baseline $\mathrm{HbA}_{1 \mathrm{c}}$ ) had a greater risk of hypoglycemia than patients with better glycemic control, regardless of treatment group. ${ }^{9}$ In the Action in Diabetes and Vascular Disease: Preterax and Diamicron Modified Release Controlled Evaluation trial, the intensively treated group showed an increased incidence of hypoglycemia, compared with the standard group (2.7\% versus $1.5 \%$; hazard ratio [HR], 1.86; $95 \%$ confidence interval $[\mathrm{CI}] 1.42-2.40 ; P<0.001) .{ }^{10}$ The findings of these outcomes trials further support the need for modifying patient therapy on the basis of individualized risks, including patients with increased risk for hypoglycemia and

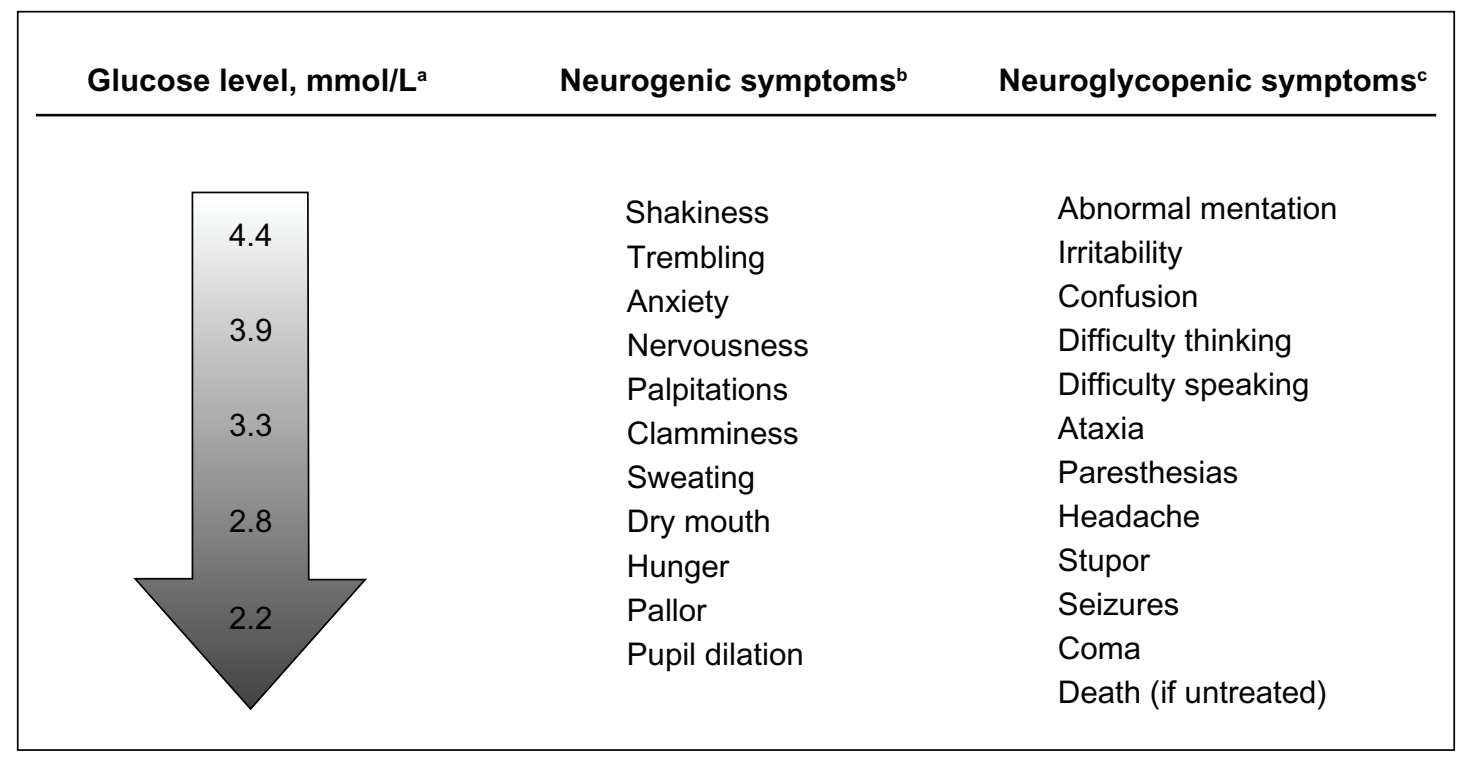

Figure I Hypoglycemia: Critical point of care in diabetes management. ${ }^{7}$ Copyright 2006. Reprinted with permission from the American Diabetes Association, Briscoe VJ, Davis SN. Hypoglycemia in type I and type 2 diabetes: Physiology, pathophysiology and management. Clin Diabetes. 2006;24:1 I5-I21.

Notes: ${ }^{\mathrm{a} m m o l} / \mathrm{L} \times 18=\mathrm{mg} / \mathrm{dL}$; ${ }^{\mathrm{C}} \mathrm{Caused}$ by falling glucose levels; ${ }^{\mathrm{c} C}$ aused by brain neuronal glucose deprivation. 
selected populations where an aggressive glucose-lowering approach may not be appropriate.

Additionally, hypoglycemic events have been linked to an increased risk of morbidity and mortality in hospitalized patients, with or without T2DM. In ambulatory patients, Desouza et al reported an increased risk of cardiac ischemia during hypoglycemia. ${ }^{11}$ In a prospective, randomized trial of 1200 adult patients admitted to an intensive care unit, patients were divided into an intensive insulin treatment group (blood glucose maintained from 4.4 to $6.1 \mathrm{mmol} / \mathrm{L}$ [80 to $110 \mathrm{mg} / \mathrm{dL}$ ]) and a standard care group (insulin therapy if blood glucose $>11.9 \mathrm{mmol} / \mathrm{L}[>215 \mathrm{mg} / \mathrm{dL}]){ }^{12}$ Although intensive insulin therapy reduced morbidity, mortality was not reduced. Using regression analysis, hypoglycemia was identified as an independent risk factor for death in insulin-treated intensive care unit patients; the authors speculated that the associated hypoglycemia might have eliminated a significant mortality benefit in the intensive therapy group. ${ }^{12}$ On the other hand, Mellbin et al reported that hypoglycemia during hospitalization was not an independent predictor of future morbidity or mortality in cardiac patients with T2DM; however, hypoglycemia was more prevalent in high-risk patients (eg, those with long-standing T2DM). ${ }^{13}$

A recent retrospective cohort study assessed the occurrence of severe hypoglycemic events (requiring hospitalization) in T2DM patients (mean age 65 years) and potential associated risk of dementia later in life. ${ }^{14}$ Of the $>16,000$ T2DM patients from the Kaiser Permanente system, $8.8 \%$ had at least one episode of hypoglycemia. Patients with two episodes of severe hypoglycemia had an increased risk of dementia (HR, $1.80 ; 95 \%$ CI $1.37-2.36$ ). This study suggested a potentially modifiable mechanism of dementia. One underlying study limitation, however, was the use of electronic records rather than standardized assessments. ${ }^{14}$

\section{Clinical recommendations}

In their position statement on glycemic control and cardiovascular events on behalf of the American Diabetes Association, Skyler et al stated that issues associated with hypoglycemia unawareness could be particularly problematic for patients with coexisting autonomic neuropathy, which is a significant risk factor for sudden death. ${ }^{3}$ Consideration must be given to the benefit-risk ratio of intensive glucose control in certain high-risk patient groups. ${ }^{3}$ The strategy now recommended by various professional organizations is to aim for a target $\mathrm{HbA}_{1 \mathrm{c}}<7 \%$ or $\leq 6.5 \%$ in most patients with T2DM but no history of CVD. Individualizing care is paramount, with less stringent targets recommended for patients with a long duration of T2DM, at high risk for severe hypoglycemia, and/or with multiple comorbidities. ${ }^{15,16}$ Age alone should not be the sole criterion for raising glycemic targets.

The American Association of Clinical Endocrinologists recommends that physicians encourage patients to achieve glycemic levels as near normal as possible, without inducing clinically significant hypoglycemia. ${ }^{16}$ Many of the current guidelines base their recommendations on drug profiles, including clinical efficacy and adverse events, in particular hypoglycemia risk. ${ }^{16,17}$

\section{Drug therapy}

There are several agents known to increase the risk of hypoglycemia (these include sulfonylureas, glinides, and insulin), whereas others (such as metformin, thiazolidinediones, glucagon-like peptide-1 [GLP-1] analogs, and dipeptidyl

Table I Antihyperglycemic medications for type 2 diabetes mellitus ${ }^{18}$

\begin{tabular}{|c|c|c|}
\hline Intervention & Main effects & Hypoglycemic risk \\
\hline$\alpha$-Glucosidase inhibitor & Reduces rate of polysaccharide digestion in the proximal small intestine & Low \\
\hline Amylin agonist & Slows gastric emptying and inhibits glucagon production & Low \\
\hline DPP-4 inhibitor & $\begin{array}{l}\text { Enhances effects of GLP-I and GIP; increases glucose-mediated insulin secretion } \\
\text { and suppresses glucagon secretion }\end{array}$ & Low \\
\hline Glinide & Stimulates insulin secretion & High $^{\mathrm{a}}$ \\
\hline GLP-I agonist & Potentiates glucose-stimulated insulin secretion & Low \\
\hline Insulin & Insulin replacement & High \\
\hline Metformin & Decreases hepatic glucose output & Low \\
\hline Sulfonylurea & Enhances insulin secretion & High \\
\hline Thiazolidinedione & Increases sensitivity of muscle, fat, and liver to endogenous and exogenous insulin & Low \\
\hline
\end{tabular}

Notes: ${ }^{a}$ May be less frequent with nateglinide

Abbreviations: DPP-4, dipeptidyl peptidase-4; GIP, glucose-dependent insulinotropic polypeptide; GLP-I, glucagon-like peptide-I . 
peptidase-4 [DPP-4] inhibitors) are associated with a lower occurrence of hypoglycemia (Table 1).

Sulfonylureas enhance insulin secretion and are associated with hypoglycemia, especially in the elderly. ${ }^{18}$ Chlorpropamide and glyburide are associated with more hypoglycemia than other agents in this class. ${ }^{18}$ Glinides increase insulin secretion and are also associated with hypoglycemia, although this may be less frequent than that seen with the sulfonylureas. ${ }^{18}$ Exogenous insulin preparations have all been associated with hypoglycemia, although the non-peaking and very short-acting analogs have demonstrated less of a risk. ${ }^{18}$

Metformin monotherapy, the recommended first-line therapy, is usually not associated with hypoglycemia; however, it is contraindicated with any condition that could increase the risk of lactic acidosis and in patients with increased serum creatinine $(\geq 132.6 \mu \mathrm{mol} / \mathrm{L}$ $[1.5 \mathrm{mg} / \mathrm{dL}]$, males; $\geq 123.8 \mu \mathrm{mol} / \mathrm{L}[1.4 \mathrm{mg} / \mathrm{dL}]$, females). ${ }^{18,19}$ $\alpha$-Glucosidase inhibitors slow the rate of polysaccharide digestion in the small intestine, and while less effective than other therapies, do not show evidence of hypoglycemia. ${ }^{18}$ The thiazolidinediones, rosiglitazone and pioglitazone, as monotherapy do not increase the risk for hypoglycemia. Limitations with this class of agents, however, include increased fluid retention and congestive heart failure with both agents, and a possible increase in cardiovascular risk with rosiglitazone. ${ }^{18}$

Incretin-based therapies are composed of analogs to incretins and DPP-4 inhibitors. These agents increase insulin secretion via a glucose-dependent mechanism. Exenatide is an incretin analog and binds to the glucagon-like peptide1 receptor in the pancreas to stimulate insulin secretion while slowing glucagon secretion. While exenatide has not been associated with hypoglycemia, gastrointestinal side effects, nausea, and its injectable route of administration may limit its usefulness. ${ }^{18}$ Long-acting formulations have demonstrated significantly less nausea. ${ }^{20}$ Two dipeptidyl peptidase-4 (DPP-4) inhibitors (sitagliptin and saxagliptin) are approved in the US and inhibit the enzyme that metabolizes endogenous glucagon-like peptide-1; thus, this hormone has a more prolonged effect on postprandial glucose through its effects on insulin secretion and suppression of glucagon secretion. DPP-4 inhibitor monotherapy minimizes the potential for hypoglycemia. ${ }^{18}$ Due to this low propensity for hypoglycemia, the National Institute for Health and Clinical Excellence stated a preference for DPP4 inhibitors as second-line therapy versus sulfonylureas in patients at risk for hypoglycemia. ${ }^{17}$

\section{Conclusions}

Hypoglycemia can be a limiting factor in the management of T2DM and may increase cardiovascular risk in addition to other possible acute and long-term detrimental effects. A therapeutic $\mathrm{HbA}_{1 \mathrm{c}}$ target of $<7 \%$ should be maintained, but needs to be individualized based on patient characteristics for an appropriate benefit-risk ratio. Medications such as metformin, DPP-4 inhibitors, thiazolidinediones, and injectable incretin analogs are efficacious with a low risk of hypoglycemia, and offer an important therapeutic advantage in minimizing hypoglycemic events.

\section{Acknowledgement}

The author is solely responsible for the content of this review. Funding for this review was provided by Bristol-Myers Squibb and AstraZeneca. Medical writing and editorial assistance for this manuscript was provided by Trina Ricci, $\mathrm{PhD}$, of Quintiles.

\section{Disclosures}

Dr Kushner has served on advisory boards for AstraZeneca, Bristol-Myers Squibb, and Eli Lilly and Company. She has served as a consultant for Eli Lilly and Company, and has been an investigator for Bristol-Myers Squibb and AstraZeneca.

\section{References}

1. Gerstein HC, Miller ME, Byington RP, et al. Action to Control Cardiovascular Risk in Diabetes Study Group. Effects of intensive glucose lowering in type 2 diabetes. N Engl J Med. 2008;358:2545-2559.

2. Dluhy RG, McMahon GT. Intensive glycemic control in the ACCORD and ADVANCE trials. $N$ Engl J Med. 2008;358:2630-2633.

3. Skyler JS, Bergenstal R, Bonow RO, et al. American Diabetes Association; American College of Cardiology Foundation; American Heart Association. Intensive glycemic control and the prevention of cardiovascular events: Implications of the ACCORD, ADVANCE, and VA diabetes trials: A position statement of the American Diabetes Association and a scientific statement of the American College of Cardiology Foundation and the American Heart Association. Diabetes Care. 2009;32:187-192.

4. Davis SN, Mann S, Briscoe VJ, Ertl AC, Tate DB. Effects of intensive therapy and antecedent hypoglycemia on counterregulatory responses to hypoglycemia in type 2 diabetes. Diabetes. 2009;58:701-709.

5. Cryer PE, Axelrod L, Grossman AB, et al. Evaluation and management of adult hypoglycemic disorders: An Endocrine Society Clinical Practice Guideline. J Clin Endocrinol Metab. 2009;94:709-728.

6. McCrimmon RJ, Deary IJ, Gold AE, et al. Symptoms reported during experimental hypoglycaemia: Effect of method of induction of hypoglycaemia and of diabetes per se. Diabet Med. 2003;20:507-509.

7. Briscoe VJ, Davis SN. Hypoglycemia in type 1 and type 2 diabetes: Physiology, pathophysiology and management. Clin Diabetes. 2006;24:1 $15-121$.

8. Bonds DE, Miller ME, Bergenstal RM, et al. The association between symptomatic, severe hypoglycaemia and mortality in type 2 diabetes: Retrospective epidemiological analysis of the ACCORD study. BMJ. 2010 Jan 8;340:b4909. doi: 10.1136. 
9. Miller ME, Bonds DE, Gerstein HC, et al. The effects of baseline characteristics, glycaemia treatment approach, and glycated haemoglobin concentration on the risk of severe hypoglycaemia: Post hoc epidemiological analysis of the ACCORD study. BMJ. 2010;8;340:b5444. doi: 10.1136/bmj.b5444

10. Patel A, MacMahon S, Chalmers J, et al. ADVANCE Collaborative Group. Intensive blood glucose control and vascular outcomes in patients with type 2 diabetes. $N$ Engl J Med. 2008;358:2560-2572.

11. Desouza C, Salazar H, Cheong B, Murgo J, Fonseca V. Association of hypoglycemia and cardiac ischemia: A study based on continuous monitoring. Diabetes Care. 2003;26:1485-1489.

12. Van den Berghe $\mathrm{G}$, Wilmer A, Hermans $\mathrm{G}$, et al. Intensive insulin therapy in the medical ICU. N Engl J Med. 2006;354:449-461.

13. Mellbin LG, Malmberg K, Waldenstrom A, Wedel H, Ryden L, DIGAMI 2 Investigators. Prognostic implications of hypoglycaemic episodes during hospitalisation for myocardial infarction in patients with type 2 diabetes: A report from the DIGAMI 2 trial. Heart. 2009;95:721-727.

14. Whitmer RA, Karter AJ, Yaffe K, Quesenberry CP Jr, Selby JV. Hypoglycemic episodes and risk of dementia in older patients with type 2 diabetes mellitus. JAMA. 2009;301:1565-1572.
15. American Diabetes Association. Standards of medical care in diabetes - 2009. Diabetes Care. 2009;32(Suppl 1):S13-S61.

16. Rodbard HW, Jellinger PS, Davidson JA, et al. Statement by an American Association of Clinical Endocrinologists/American College of Endocrinology Consensus Panel on Type 2 Diabetes Mellitus: An algorithm for glycemic control. Endocr Pract. 2009; 15:540-559.

17. National Institute for Health and Clinical Excellence. 2009. Type 2 diabetes: Newer agents for blood glucose control in type 2 diabetes. Available at: http://www.nice.org.uk/nicemedia/pdf/ CG87ShortGuideline.pdf. Accessed September 30, 2009.

18. Nathan DM, Buse JB, Davidson MB, et al. Medical management of hyperglycemia in type 2 diabetes: A consensus algorithm for the initiation and adjustment of therapy: A consensus statement of the American Diabetes Association and the European Association for the Study of Diabetes. Diabetes Care. 2009;32:193-203.

19. Glucophage [package insert]. Princeton, NJ: Bristol-Myers Squibb; 2009.

20. Drucker DJ, Buse JB, Taylor K, et al; DURATION-1 Study Group. Exenatide once weekly versus twice daily for the treatment of type 2 diabetes: A randomised, open-label, non-inferiority study. Lancet. 2008;372:1240-1250.

\section{Publish your work in this journal}

Diabetes, Metabolic Syndrome and Obesity: Targets and Therapy is an international, peer-reviewed open-access journal committed to the rapid publication of the latest laboratory and clinical findings in the fields of diabetes, metabolic syndrome and obesity research. Original research, review, case reports, hypothesis formation, expert opinion and commentaries are all considered for publication. The manuscript management system is completely online and includes a very quick and fair peer-review system, which is all easy to use. Visit http://www.dovepress.com/testimonials.php to read real quotes from published authors. 